\title{
Differentiation of porphyria cutanea tarda symptomatica from other types of porphyria by measurement of isocoproporphyrin in faeces
}

\author{
G. H. ELDER \\ From the Department of Medical Biochemistry, Welsh National School of Medicine, Heath Park, \\ Cardiff CF4 4 XN
}

SYNOPSIS The faecal porphyrin patterns of 24 patients with porphyria cutanea tarda symptomatica (PCTS), eight patients with variegate porphyria, three patients with other types of porphyria, and 20 non-porphyric subjects have been compared using a two-dimensional thin layer chromatographic technique that separates porphyrins of the isocoproporphyrin series from other faecal porphyrins. The 'isocoproporphyrin':coproporphyrin ratio ranged from 0.1 to 5.6 for patients with PCTS, whereas in other types of porphyria and non-porphyric subjects it was 0.05 or less.

Porphyria cutanea tarda symptomatica (PCTS) is a syndrome characterized by skin lesions, overproduction of porphyrins with four to eight carboxylic acid side chains, and the absence of the acute attacks of porphyria, often induced by drugs, which are an important feature of the other hepatic porphyrias (Taddeini and Watson, 1968; Dowdle et al, 1970). It is the commonest type of cutaneous hepatic porphyria in the United Kingdom and is seen most frequently in middle-aged men with alcoholic liver disease, although it also occurs in association with other types of liver disease and in patients taking oestrogens. PCTS in more than one member of a family is rare (Dehlin et al, 1973). Hepatic siderosis is frequent and the condition is particularly common where iron overload and alcoholism occur together, as among the Bantu in South Africa. Depletion of body iron stores by repeated venesection leads to remission in the majority of patients (Ramsay et al, 1974).

The main problem in the diagnosis of PCTS is differentiation from variegate porphyria (VP). Since the skin lesions in both conditions are identical, and may be the sole clinical manifestation, the distinction depends on differences in the patterns of excretion of haem precursors (Eales et al, 1963). Recently, it has been shown that the faeces of patients with PCTS contain a previously unrecognized group of tetracarboxylate porphyrinsisocoproporphyrin, de-ethylisocoproporphyrin, dehydroisocoproporphyrin, and hydroxyisocopropor-

Received for publication 19 March 1975. phyrin (Elder, 1971a, 1972). The probable origin and metabolism of these porphyrins has been described (Elder, 1974). This paper assesses their diagnostic significance.

\section{Patients and Methods}

\section{PATIENTS}

Patients with porphyria were classified according to current clinical and biochemical criteria (Elder et al, 1972). Table I shows the results of measurements of haem precursors in urine and faeces for the patients with hepatic porphyria. Twenty-four patients with PCTS were studied, 19 Europeans and five Bantu. Six of the former were in remission when investigated. Of the European patients, 10 had liver damage due to alcohol, two had cryptogenic cirrhosis, one had infective hepatitis, four developed PCTS while on oral contraceptives, and in two patients no aetiological agent was implicated. The eight patients with variegate porphyria came from six apparently unrelated European families. Clinical details of the patients with erythropoietic protoporphyria and congenital erythropoietic porphyria have been published (Nicholson et al, 1973).

Twenty subjects without clinical or biochemical evidence of porphyria were also studied. Of these, eight were normal, six were in hospital for minor surgery, three had alcoholic cirrhosis, and three had cryptogenic cirrhosis. Two of the patients with liver disease had hyperbilirubinaemia (serum bilirubin 46 and $102 \mu \mathrm{mol} / \mathrm{l})$. 


\begin{tabular}{|c|c|c|c|c|c|c|c|c|}
\hline & \multirow{2}{*}{$\begin{array}{l}\text { No. of } \\
\text { Patients }\end{array}$} & \multicolumn{3}{|l|}{ Urine } & \multicolumn{4}{|l|}{ Faeces } \\
\hline & & $\begin{array}{l}P B G \\
(\mu \mathrm{mol} / 24 h)\end{array}$ & $\begin{array}{l}\text { Copro } \\
(\mathrm{nmol} / 24 h)\end{array}$ & $\begin{array}{l}\text { Uro } \\
\text { (nmol/24h) }\end{array}$ & $\begin{array}{l}\text { Copro } \\
\text { (nmol/g dry wt) }\end{array}$ & Proto & $\begin{array}{l}\text { Proto } \\
\text { Copro ratio }\end{array}$ & $\begin{array}{l}\text { Etherinsol } \\
(n m o l / g \text { dry wt) }\end{array}$ \\
\hline \multicolumn{9}{|l|}{ PCTS } \\
\hline $\begin{array}{l}\text { Active } \\
\text { Remission } \\
\text { Bantu }\end{array}$ & $\begin{array}{l}6 \\
5\end{array}$ & & $\begin{array}{l}527(12) \\
223-947 \\
316 \\
88-656 \\
736 \\
64-1510\end{array}$ & $\begin{array}{l}4848 \\
2031-12274 \\
779 \\
542-1276 \\
3213 \\
709-7497\end{array}$ & $\begin{array}{l}188 \\
108-395 \\
108 \\
38-223 \\
87 \\
22-197\end{array}$ & $\begin{array}{l}174 \\
55-468 \\
171 \\
30-498 \\
57 \\
30-121\end{array}$ & $\begin{array}{l}0.97 \\
0.36-2.06 \\
1.60 \\
0 \cdot 51-3.50\end{array}$ & $\begin{array}{l}219(12) \\
36-430 \\
100(5) \\
13-166 \\
26 \\
7-40\end{array}$ \\
\hline Variegate & 8 & $\begin{array}{l}49 \\
0-186\end{array}$ & $\begin{array}{l}2380(6) \\
43-7890\end{array}$ & $\begin{array}{l}480(4) \\
95-1155\end{array}$ & $\begin{array}{l}456 \\
113-1313\end{array}$ & $\begin{array}{l}934 \\
345-2064\end{array}$ & $\begin{array}{l}2 \cdot 38 \\
1 \cdot 57-3 \cdot 05\end{array}$ & $\begin{array}{l}418 \\
50-1095\end{array}$ \\
\hline Acute intermittent & 1 & 58 & & & 43 & 153 & & 28 \\
\hline Normal range & & $<9$ & $<244$ & $<36$ & $<41$ & $<135$ & & $<24$ \\
\hline
\end{tabular}

Table I Haem precursors in urine and faeces

The mean and range is shown for each estimation. Figures in parentheses indicate number of patients when this is less than the total in the group Porphobilinogen (PBG) excretion was normal in all patients with PCTS.

\section{PORPHYRINS}

Porphyrins for use as standards were isolated as their methyl ester derivatives from porphyric urine or faeces, as described by Elder (1972).

EXTRACTION OF PORPHYRINS FROM FAECES Porphyrins were extracted from faeces (0.5-1.0 g wet weight) with ether acetic acid, as described by Rimington (1971). The total volume of the etheracetic acid extract was measured, and an aliquot $(0 \cdot 2-0 \cdot 4 \mathrm{vol})$ was taken for estimation of the coproporphyrin and protoporphyrin fractions (Rimington, 1971). The porphyrins in the rest of the extract were transferred to $1.4 \mathrm{M}-\mathrm{HCl}$ by shaking with successive volumes $(2-5 \mathrm{ml})$ of acid until no more porphyrin was extracted. The $\mathrm{pH}$ of the acid extract was adjusted to $\mathrm{pH} 3.5$ with saturated aqueous sodium acetate, and talc (acid-washed) was added in batches until all porphyrin was absorbed. The talc was removed by filtration, washed with water, and partially dried by suction. Porphyrins were eluted from the moist talc with methanol- $\mathrm{H}_{2} \mathrm{SO}_{4}(19: 1, \mathrm{v} / \mathrm{v})$ and the eluate was kept in the dark at room temperature for 20 hours to allow complete esterification. The porphyrin methyl esters were transferred to chloroform (Falk, 1964), which was washed once with $2 \mathrm{M}-\mathrm{NH}_{4} \mathrm{OH}$ and three times with water, dried by filtration through chloroform-moistened paper, and removed by distillation at $40-50^{\circ} \mathrm{C}$ under reduced pressure.

MEASUREMENT OF PORPHYRIN RATIOS

Porphyrin methyl esters were fractioned by twodimensional thin-layer chromatography on silica gel plates (Camag D5 or Merck silica gel 60) (Elder, 1971b). In this system the methyl esters of three members of the isocopioporphyrin series-isocoproporphyrin, de-ethylisocoproporphyrin, and de- hydroisocoproporphyrin - migrate together as a single spot between coproporphyrin and 'pentacarboxylic porphyrin methyl esters (fig 1). Porphyrins migrating in this position and identified by co-chromatography with authentic isocoproporphyrin methyl ester, but not identified further, are subsequently referred to as 'isocoproporphyrin'.

Coproporphyrin, 'isocoproporphyrin', and hydroxyisocoproporphyrin were recovered from the silica gel by elution with chloroform-methanol $(4: 1, \mathrm{v} / \mathrm{v})$. The eluates were made up to the same volume, usually 3.0 or $4.0 \mathrm{ml}$, and the concentration of porphyrin in each was determined by spectrophotometry using the millimolar extinction coefficient for coproporphyrin tetramethyl ester in chloroform given by Falk (1964). 'Isocoproporphyrin': coproporphyrin and hydroxyisocoproporphyrin:coproporphyrin ratios were obtained by dividing the concentration of porphyrin in the appropriate eluate by the concentration of the coproporphyrin eluate. Mixtures of isocoproporphyrin and coproporphyrin esters containing as little as $2 \%$ of the former could be separated by this technique.

SCREENING TEST FOR "ISOCOPROPORPHYRIN" IN FAECES

About $0.5 \mathrm{~g}$ wet faeces was suspended in $4.0 \mathrm{~m}$ methanol- $\mathrm{H}_{2} \mathrm{SO}_{4}(9: 1, \mathrm{v} / \mathrm{v})$ for 48 hours in the dark at room temperature. After centrifugation, the supernatant was removed, and mixed with $2.0 \mathrm{ml}$ chloroform, and the esters were recovered as described above. An aliquot of this extract containing sufficient porphyrin, as judged by the intensity of red fluorescence in ultraviolet light, was applied as a $2 \mathrm{~cm}$ streak to a $200 \times 200 \times 0.25 \mathrm{~mm}$ silica gel 60 plate (Merck), fractionated by one-dimensional thin-layer chromatography in chloroform-kerosenemethanol (200:100:6, by vol) (Elder, 1971b), and 


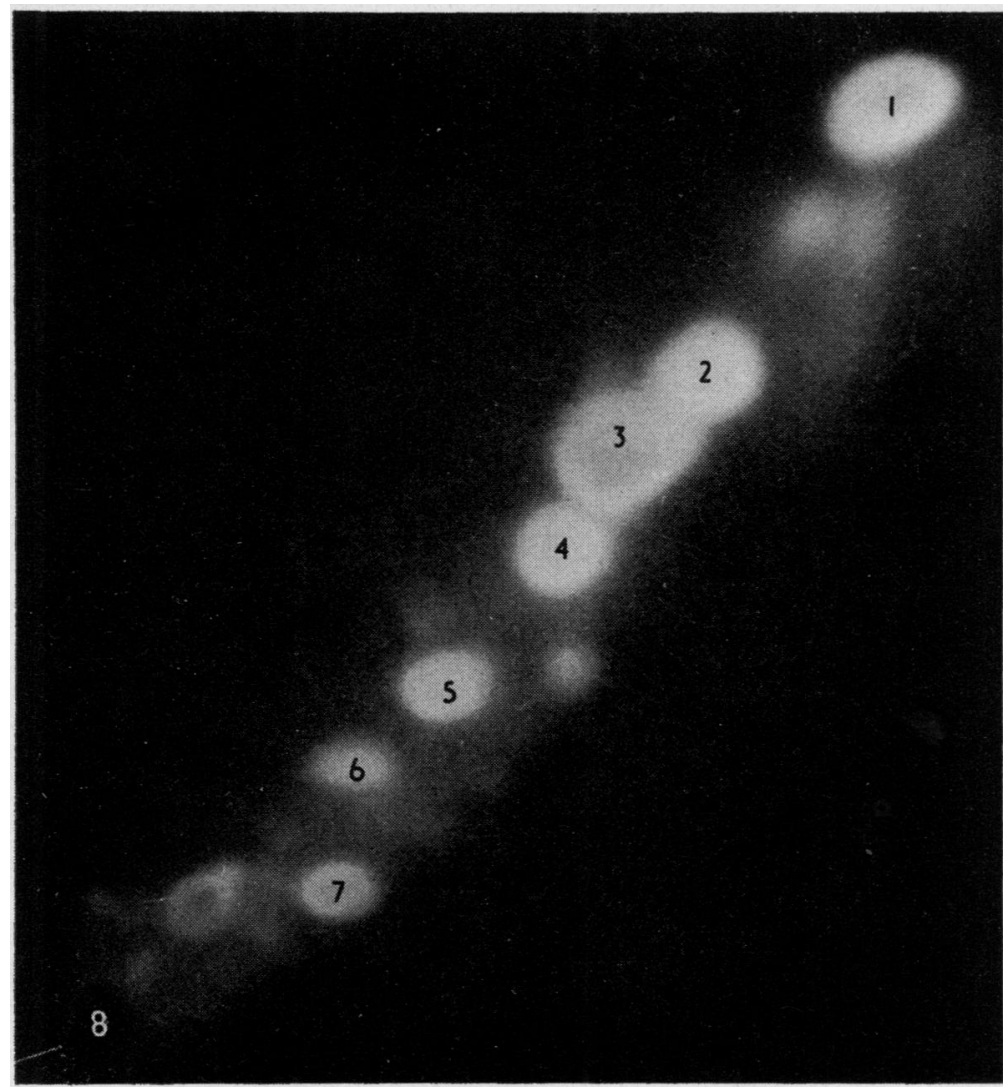

Fig 1 Two-dimensional thinlayer chromatography of porphyrin esters from the faeces of a patient with PCTS photographed under ultraviolet light: 1 = protoporphyrin; 2 = coproporphyrin; 3 = 'isocoproporphyrin'; 4, 5, 6 = penta-, hexa-, and hepta-carboxylic porphyrins; 7 = hydroxyisocoproporphyrin: 8 = origin.

inspected under ultraviolet light for the presence of a porphyrin migrating between coproporphyrin and pentacarboxylic porphyrin esters. The identity of any porphyrin detected in this position was confirmed by two-dimensional thin-layer chromatography.

\section{OTHER METHODS}

Faecal ether-insoluble porphyrins ('X-porphyrin' fraction) were measured as described by Rimington et al (1968). Urinary porphobilinogen, coproporphyrin, and uroporphyrin fractions were determined by the methods of Mauzerall and Granick (1956) and Rimington (1971). Urine porphyrins were isolated as their methyl esters (Dowdle et al, 1970), fractionated, and estimated as described above.

\section{Results}

Porphyrins of the isocoproporphyrin series were identified in the faeces of all patients with PCTS and of three of the eight patients with VP. Hydroxy- isocoproporphyrin was always present in smaller amounts than 'isocoproporphyrin'. The screening test using one-dimensional thin-layer chromatography was as effective as the two-dimensional thinlayer chromatography technique for the detection of 'isocoproporphyrin'. A typical chromatogram illustrating the difference between the faecal porphyrin excretion patterns of PCTS and VP is shown (fig 2).

Porphyrins of the isocoproporphyrin series were present in the urine from four of the six patients with PCTS in which the urine porphyrins were fractionated by thin-layer chromatography (table II). The figures for porphyrin excretion in these patients indicate that in PCTS isocoproporphyrin and related porphyrins are predominantly excreted in the faeces, as reported previously (Elder, 1971a, 1974).

Trace amounts of a porphyrin migrating between coproporphyrin and pentacarboxylic porphyrin esters, and therefore tentatively identified as belonging to the isocoproporphyrin series, were detected in the faeces of four of the 20 non-porphyric 


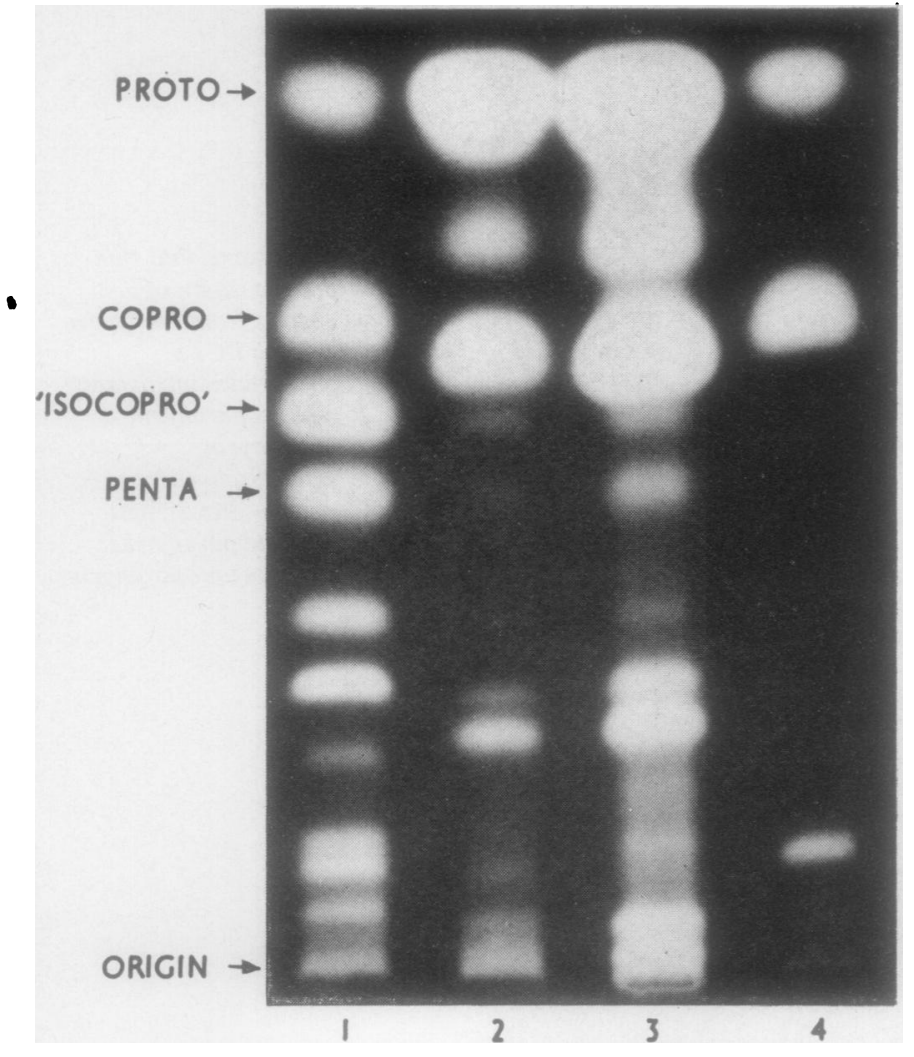

Fig 2 Screening test for

'isocoproporphyrin'. Thin-layer chromatography of porphyrin esters from faeces of patients with PCTS (1) and VP $(2,3)$ and a normal subject $(4)$ photographed under ultraviolet light.

subjects, one of these being a patient with cirrhosis. Hydroxyisocoproporphyrin was not detected in the faeces from any of the non-porphyric subjects.

Figure 3 shows that the 'isocoproporphyrin': coproporphyrin ratio is higher in PCTS than in other types of porphyria and that measurement of this ratio is an effective way of differentiating PCTS and VP. Thus, with the exception of two of the patients investigated during remission, there is at

\begin{tabular}{|c|c|c|c|c|}
\hline \multirow[t]{2}{*}{ Patient } & \multicolumn{2}{|l|}{ Urine } & \multicolumn{2}{|l|}{ Faeces } \\
\hline & $\begin{array}{l}\text { Total } \\
\text { Porphyrin } \\
(\mathrm{nmol} / 24 h)\end{array}$ & $\begin{array}{l}\text { Isocopro } \\
\text { Series }^{1} \\
(n m o l / 24 h)\end{array}$ & $\begin{array}{l}\text { Copro } \\
\text { Fraction } \\
(n m o l / 24 h)^{2}\end{array}$ & $\begin{array}{l}\text { 'Isocopro': } \\
\text { Copro Ratio }\end{array}$ \\
\hline 6 & 12805 & 17 & 3450 & $5 \cdot 6$ \\
\hline 7 & 6928 & 0 & 2687 & $2 \cdot 2$ \\
\hline 8 & 2006 & 5 & 7908 & 0.5 \\
\hline 9 & 2825 & 0 & 2168 & $2 \cdot 8$ \\
\hline 10 & 5292 & 652 & 2687 & $3 \cdot 8$ \\
\hline 11 & 6723 & 67 & 3664 & $2 \cdot 6$ \\
\hline
\end{tabular}

Table II Excretion of isocoproporphyrin series in urine and faeces

'Hydroxyisocoproporphyrin always less than 'isocoproporphyrin': ${ }^{2}$ Calculated assuming $\mathbf{2 0} \mathrm{g}$ dry weight of faeces per day least a 10 -fold difference in the ratio between the two conditions. In PCTS there was no correlation between the ratio and the level of any faecal porphyrin fraction.

In PCTS the excretion of uroporphyrin decreases progressively during remission. The isocoproporphyrin':coproporphyrin ratio is also lower during remission (fig 3 ) and there is a statistically significant correlation between the ratio and urinary uropor-

\begin{tabular}{|c|c|c|c|c|c|c|}
\hline \multirow[t]{2}{*}{ Patient } & \multicolumn{2}{|c|}{$\begin{array}{l}\text { Urine } \\
(\mathrm{nmol} / 24 h)\end{array}$} & \multicolumn{3}{|c|}{$\begin{array}{l}\text { Faeces } \\
(\mathrm{nmol} / \mathrm{g} d r y w t)\end{array}$} & \multirow[t]{2}{*}{$\begin{array}{l}\text { Isocopro } \\
\text { Ratio }\end{array}$} \\
\hline & Copro & Uro & Copro & Proto & $\begin{array}{l}\text { Ether- } \\
\text { insol }\end{array}$ & \\
\hline 1 & 174 & 54 & 26 & 57 & 49 & 0.9 \\
\hline 2 & 60 & 75 & 47 & 60 & 31 & 1.9 \\
\hline 3 & 122 & 42 & 87 & 206 & 49 & $0 \cdot 2$ \\
\hline $4 a$ & 101 & 542 & 60 & 30 & 13 & 0.2 \\
\hline b & 67 & 6 & 11 & 48 & 8 & 0.0 \\
\hline $5 a$ & 131 & 391 & 8 & 57 & 13 & 0.5 \\
\hline b & 99 & 26 & 6 & 112 & 13 & 0.0 \\
\hline
\end{tabular}

Table III PCTS:porphyrin excretion after prolonged remission

$a=$ first measurement in remission $b=15-16$ months later. Normal values as in table $I$. Abnormal values are in italics. 


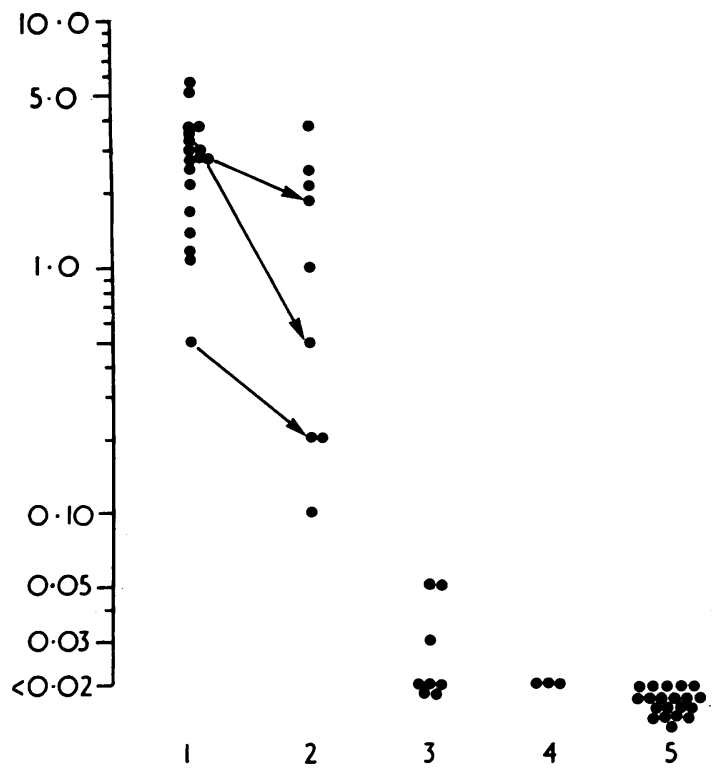

Fig 3 'Isocoproporphyrin' : coproporphyrin ratios. $1=$ active $P C T S ; 2=P C T S$ in remission; $3=V P$; 4 = other porphyrias (see text); 5 = non-porphyric subjects. Isocoproporphyrin was detected in four of the non-porphyric subjects but the ratio could not be measured and has been recorded as $<0.02$. Arrows indicate measurements on faeces from the same patient before and after treatment by venesection.

phyrin excretion (for 27 patients, $r=0.45, \mathrm{P}<0.05$ ). When remission is prolonged and porphyrin excretion has returned almost to normal, urinary uroporphyrin excretion and the 'isocoproporphyrin': coproporphyrin ratio are more likely to be abnormal than the other measurements of porphyrin excretion shown in table III.

\section{Discussion}

When VP presents with skin lesions unaccompanied by porphobilinogenuria it can usually be differentiated from PCTS by measurement of urinary and faecal porphyrin fractions using solvent paitition techniques (Eales et al, 1963) (table I). Thus in VP the main abnormality is a marked increase in the excretion of porphyrins in the faeces, the concentration of porphyrin in the protoporphyrin fraction usually being about twice that in the coproporphyrin fraction. Urinary porphyrin excretion may occasionally be normal, but in most patients there is some increase in coproporphyrin excretion. In PCTS, on the other hand, the characteristic abnormality is a great increase in the excretion of uroporphyrin in the urine, the rate of excretion always exceeding that of coproporphyrin. The faecal porphyrin fractions are usually no more than moderately increased, with an increase in the coproporphyrin fraction as the most consistent abnormality (Eales et al, 1966). In a few patients difficulties in diagnosis arise because the concentration of uroporphyrin in the urine in VP may occasionally be greater than that of coproporphyrin, due to in vitro condensation of porphobilinogen, and because in a few patients faecal porphyrin excretion may be as great in PCTS as in VP (Eales et al, 1966) (table I). In such patients it is convenient if a diagnosis can be made without collection of further samples of urine and faeces from the patient and other family members.

In recent years a number of methods for distinguishing between VP and PCTS that depend on measurement of individual porphyrins rather than porphyrin fractions have been described. Rimington et al (1968) reported that patients with VP excrete increased amounts of porphyrin-peptide conjugates ('X porphyrin'), mainly in their faeces, and suggested that determination of ' $X$ porphyrin' may be of diagnostic value. It is now clear that measurement of the ' $\mathrm{X}$ porphyrin' fraction of faeces is no more effective than estimation of the ether-soluble porphyrin fractions as a means of distinguishing VP from PCTS (Eales et al, 1971; Moore et al, 1972; Elder et al, 1974). Although the composition of this fraction is different in the two conditions (Elder et al, 1974), methods of analysis are too laborious for routine use. Other methods involve quantitative assessment of porphyrin excretion patterns. Thus, Doss et al (1971) have used thin-layer chromatography with fluorescence scanning to separate and measure urine porphyrins and have defined characteristic patterns for each of the hepatic porphyrias. Grosser and Eales (1973) used a similar thin-layer chromatographic method to examine the faecal porphyrin patterns of PCTS and VP but concluded that separation of the two conditions was no better than with solvent partition techniques. Their thinlayer chromatography system did not separate 'isocoproporphyrin' from coproporphyrin and pentacarboxylate porphyrin.

Figure 3 shows that measurement of the 'isocoproporphyrin' :coproporphyrin ratio in faeces is a reliable method of separating PCTS and VP. Although in the present series it was no more effective in this respect than the combination of measurements in table $I$, the technique was useful as a confirmatory test in the few patients with PCTS with high faecal porphyrin levels and in the one patient with VP in whom there was more uroporphyrin than coproporphyrin in the urine. Furthermore, the results reported here suggest that in the 
majority of patients with PCTS increased excretion of porphyrins of the isocoproporphyrin series is to a large extent responsible for the increase in the faecal coproporphyrin fraction that has been considered a characteristic feature of the condition (Eales et al, 1966; Taddeini and Watson, 1968). The results in table III show that measurement of the 'isocoproporphyrin':coproporphyrin ratio is likely to be useful for assessing the significance of minor abnormalities of porphyrin excretion, particularly when these are found in the relatives of patients with PCTS and in patients with liver disease, both situations in which latent PCTS may be commoner than previously suspected (Doss et al, 1971; Dehlin et al, 1973).

It is not clear whether the absence of 'isocoproporphyrin' from the faeces of the majority of normal subjects and patients with types of porphyria other than PCTS reflects a true failure to form or excrete these porphyrins or whether it is explained by a lack of sensitivity in the method of detection, the lower limit of detectability coinciding with the upper end of the normal range for the ratio. Unfortunately, when 'isocoproporphyrin' was detected in normal faeces, the ratio could not be measured because, due to the large amount of non-porphyrin material relative to porphyrin in the extracts, it was impossible to apply sufficient porphyrin to the plates to obtain measurable amounts of 'isocoproporphyrin'. Thus it is not possible to say whether the 'isocoproporphyrin':coproporphyrin ratio, as well as the concentration of 'isocoproporphyrin' in the faeces, was higher in the three patients with VP than in the four non-porphyric subjects.

The excretion of porphyrins of the isocoproporphyrin series by some patients with VP, by a patient with atypical congenital erythropoietic porphyria (Rimington and With, 1973; Eriksen and Eriksen, 1974), and by some normal subjects, emphasizes that these porphyrins, like the other porphyrins excreted in excess in PCTS, are not metabolites unique to this condition. It is probable that in both liver and erythropoietic cells pentacarboxylate porphyrinogen III can be metabolized either to coproporphyrinogen III or to dehydroisocoproporphyrinogen, the precursor of porphyrins of the isocoproporphyrin series (Elder, 1972). In normal circumstances, coproporphyrinogen III is the major product. In PCTS, pentacarboxylate porphyrinogen accumulates and the proportion converted to dehydroisocoproporphyrinogen appears to be greatly increased.

Eriksen and Eriksen (1974) have suggested that the conversion of pentacarboxylate porphyrinogen III to coproporphyrinogen III is impaired in the bone marrow of their patient with atypical congenital erythropoietic poiphyria and that as a result pentacarboxylate porphyrinogen is metabolized to protoporphyrin IX via dehydroisocoproporphyrinogen, thus bypassing coproporphyrinogen III. Although it is possible that the same alternative route is important as a pathway for haem synthesis in the liver in PCTS, it is more likely that the same biochemical defect which leads to accumulation of pentacarboxylate porphyrinogen in PCTS prevents metabolism of dshydroisocoproporphyrinogen, since utilization of each compound for haem synthesis involves decarboxylation of the acetate $\beta$-substituent that is common to both.

I thank Professor C. H. Gray of the Department of Chemical Pathology, King's College Hospital Medical School, where much of this work was done, for advice and encouragement; Professor S. M. Joubert, of the Department of Chemical Pathology, University of Natal, Durban, South Africa, and Professor I. A. Magnus, of the Institute of Dermatology, London E9, for sending samples for analysis: and the Medical Research Council for a Clinical Research Fellowship.

\section{References}

Dehlin, O., Enerbäck, L., and Lundvall, O. (1973). Porphyria cutanea tarda - a genetic disease? Acta med. scand., 194, 265-270.

Doss, M., Meinhof, W., Look, D., Henning, H., Nawrocki, P., Dölle, W., Strohmeyer, G., and Filippini, L. (1971). Porphyrins in liver and urine in acute intermittent and chronic hepatic porphyrias. S. Afr. J. Lab. clin. Med. $17,50-56$.

Dowdle, E., Goldswain, P., Spong, N., and Eales, L. (1970) The pattern of porphyrin isomer accumulation and ex cretion in symptomatic porphyria. Clin. Sci., 39, 147-158.

Eales, L., Dowdle, E. B., Saunders, S. J., and Sweeney, G. D. (1963). The diagnostic importance of faecal porphyrins in the differentiation of the porphyrias. II. Values in the cutaneous porphyrias. S. Afr. J. Lab. clin. Med., 9, 126-134.

Eales, L., Grosser, Y., and Sano, S. (1971). The porphyrin peptides: practical implications. S. Afr. J. Lab. clin. Med., 17, 160-163.

Eales, L., Levey, M. J., and Sweeney, G. D. (1966). The place of screening tests and quantitative investigations in the diagnosis of the porphyrias with particular referenc to variegate and symptomatic porphyria. S. Afr. med. J., 40, 63-71.

Elder, G. H. (1971a). The porphyrin excretion pattern of symptomatic porphyria. S. Afr. J. Lab. clin. Med., 17, 45 50.

Elder, G. H. (1971b). Separation of porphyrin methyl esters by two dimensional thin-layer chromatography.J. Chromat. 59, 234-236.

Elder, G. H. (1972). Identification of a group of tetracarboxylate porphyrins, containing one acetate and three propionate $\beta$-substituents, in faeces from patients with symptomatic cutaneous hepatic porphyria and from rats with porphyria due to hexachlorobenzene. Biochem. J., 126, 877-891.

Elder, G. H. (1974). The metabolism of porphyrins of the isocoproporphyrin series. Enzyme, 17, 61-68. 
Elder, G. H., Gray, C. H., and Nicholson, D. C. (1972). The porphyrias: a review. J. clin. Path., 25, 1013-1033.

Elder, G. H., Magnus, I. A., Handa, F., and Doyle, M. (1974). Faecal ' $X$ porphyrin' in the hepatic porphyrias. Enzyme, 17, 29-38.

Eriksen, L. and Eriksen, N. (1974). Porphyrin distribution and porphyrin excretion in human congenital erythropoietic porphyria. Scand. J. clin. Lab. Invest., 33, 323-332.

Falk, J. E. (1964). Porphyrins and Metalloporphyrins. Elsevier, Amsterdam, London and New York.

Grosser, Y. and Eales, L. (1973). Patterns of faecal porphyrin excretion in the hepatocutaneous porphyrias. S. Afr. med. J., 47, 2162-2168.

Mauzerall, D. and Granick, S. (1956). The occurrence and determination of $\delta$-aminolevulinic acid and porphobilinogen in urine. J. biol. Chem., 219, 435-446.

Moore, M. R., Thompson, G. C., and Goldberg, A. (1972). Amounts of faecal porphyrin-peptide conjugates in the porphyrias. Clin. Sci., 43, 299-302.

Nicholson, D. C., Cowger, M. L., Kalivas, J., Thompson,
R. P. H., and Gray, C. H. (1973). Isotopic studies of the erythropoietic and hepatic components of congenital porphyria and 'erythropoietic' protoporphyria. Clin. Sci., 44, 135-150.

Ramsay, C. A., Magnus, I. A., Turnbull, A., and Baker, H. (1974). The treatment of porphyria cutanea tarda by venesection. Quart. J. Med., 43, 1-24.

Rimington, C. (1971). Quantitative determination of porphobilinogen and porphyrins in urine and porphyrins in faeces and erythrocytes. Broadsheet No. 70 (revised Broadsheet 36), Association of Clinical Pathologists.

Rimington, C., Lockwood, W. H., and Belcher, R. V. (1968). The excretion of porphyrin-peptide conjugates in porphyria variegata. Clin. Sci., 35, 211-247.

Rimington, C. and With, T. K. (1973). Porphyrin studies in congenital erythropoietic porphyria. Danish med. Bull., 20, 5-12.

Taddeini, L. and Watson, C. J. (1968). The clinical porphyrias. Semin. Haemat., 5, 335-369. 